\title{
Clot in Transit: Early Intervention with Early Recovery
}

\author{
Casey Walk ${ }^{1}$, Sarah Katchen ${ }^{1}$, and Vincent Nardy $^{2}$ \\ ${ }^{1}$ Wright State University Boonshoft School of Medicine \\ ${ }^{2}$ Premier Health Miami Valley Hospital
}

February 27, 2022

\begin{abstract}
48-year-old female presented with dyspnea and fatigue in June 2020. CT imaging found pulmonary embolus and a heparin drip was initiated. She later developed chest pain which led to an echocardiogram. This imaging noted biatrial thrombus extending through mitral and tricuspid valve, as well as through a patent foramen ovale (PFO) (Fig. 1, 2). She underwent emergent sternotomy, left and right atrial embolectomy, left and right pulmonary embolectomy, and atrial septal defect closure (Fig. 3). She progressed well post op and was discharged on postoperative day 7 on therapeutic anticoagulation. Remains in good condition on follow up on long term follow up.
\end{abstract}

Title Page

Title: Clot in Transit: Early Intervention with Early Recovery

Running Title: Clot in Transit: Early Intervention

Authors: Casey Walk, $\mathrm{MD}^{1}$, Sarah Katchen, $\mathrm{MD}^{1}$, Vincent Nardy, $\mathrm{DO}^{2}$

${ }^{1}$ Wright State University Department of Surgery, Miami Valley Hospital, Weber Center for Health Education $7^{\text {th }}$ Floor, 128 E. Apple St., Dayton, OH 45409-

${ }^{2}$ Department of Cardiothoracic Surgery, Miami Valley Hospital, 30 E. Apple St., Suite 1480, Dayton, OH 45409

Casey Walk, MD- Literature review, manuscript writing, editing

Sarah Katchen, MD- Literature review, manuscript writing, editing

Vincent Nardy, DO- supervision, manuscript editing, final approval of article

Classification: Images in Cardiothoracic Surgery

Corresponding Author: Casey T. Walk, MD

Address-Miami Valley Hospital, Weber Center for Health Education $7^{\text {th }}$ Floor, 128 E. Apple St., Dayton, OH 45409

Email: casey.walk@wright.edu

Acknowledgements and Disclosures

The authors of this study have no financial disclosures.

Abstract 
48-year-old female presented with dyspnea and fatigue in June 2020. CT imaging found pulmonary embolus and a heparin drip was initiated. She later developed chest pain which led to an echocardiogram. This imaging noted biatrial thrombus extending through mitral and tricuspid valve, as well as through a patent foramen ovale (PFO) (Fig. 1, 2). She underwent emergent sternotomy, left and right atrial embolectomy, left and right pulmonary embolectomy, and atrial septal defect closure (Fig. 3). She progressed well post op and was discharged on postoperative day 7 on therapeutic anticoagulation. Remains in good condition on follow up on long term follow up.

Text

Pulmonary embolism is a blockage of a pulmonary artery. This condition has both high morbidity and mortality ${ }^{1}$. A rare form of this embolism is referred to as a 'clot in transit', which is a thrombus that extends from the right atrium through the tricuspid valve. Estimated mortality from 'clot in transit' is estimated at approximately $45 \%^{1}$. Increasingly rare is the 'impending paradoxical embolism' (IPDE), which is defined as the thrombus extending across an atrial septal defect ${ }^{2}$. If a clot in transit is also traversing a PFO, studies have shown decreased mortality with surgical intervention when the patient is hemodynamically stable, but thrombolytic therapy if unstable, although limited research on mortality and outcome with medical management ${ }^{3}$. This study received a waiver from the IRB at our institution.

48-year-old female presented with dyspnea and fatigue in June 2020. CT imaging found pulmonary embolus and a heparin drip was initiated. She later developed chest pain which led to an echocardiogram. This imaging noted biatrial thrombus extending through mitral and tricuspid valve, as well as through a patent foramen ovale (PFO) (Fig. 1, 2). She underwent emergent sternotomy, left and right atrial embolectomy, left and right pulmonary embolectomy, and atrial septal defect closure (Fig. 3). She progressed well post op and was discharged on postoperative day 7 on therapeutic anticoagulation. Remains in good condition on follow up on long term follow up.

\section{References}

1-Ruiz-Morales, Jose, William Kogler, Maedeh Ganji, and Srinivasan Sattiraju. 2020. "Clot in Transit: A Case of Acute Pulmonary Embolism." BMJ Case Reports 13(8):e236494. doi: 10.1136/bcr-2020-236494.

2-Kabrhel, Christopher, Rachel Rosovsky, and Shannon Garvey. 2020. "Special Considerations in Pulmonary Embolism." Critical Care Clinics 36(3):531-46. doi: 10.1016/j.ccc.2020.02.008.

3-Medina, Maria A., Albert F. Guerrero, Nestor F. Sandoval, and Juan P. Umana. 2020. "Successful Surgical Treatment of Clot in Transit with Impending Paradoxical Embolism: A Case Report." JTCVS Techniques4:140-42. doi: 10.1016/j.xjtc.2020.07.019.

Figures Legends

Figure 1- Echocardiogram noting mobile clot in the right atrium with PFO.

Figure 2- Echocardiogram noting mobile clot extending through both tricuspid and mitral valve.

Figure 3- Intraoperative photographs, A) demonstrating clot visualized within the right atrium. B) Clot being removed with distal portion remaining within the PFO. C) Clot in its entirety after removal.

Figures

\section{Hosted file}

image1.emf available at https://authorea.com/users/462554/articles/557956-clot-in-transitearly-intervention-with-early-recovery

Figure 1- Echocardiogram noting mobile clot in the right atrium with PFO.

\section{Hosted file}


image2.emf available at https://authorea.com/users/462554/articles/557956-clot-in-transitearly-intervention-with-early-recovery

Figure 2- Echocardiogram noting mobile clot extending through both tricuspid and mitral valve.

\section{Hosted file}

image3.emf available at https://authorea.com/users/462554/articles/557956-clot-in-transitearly-intervention-with-early-recovery

Figure 3- Intraoperative photographs, A) demonstrating thrombus visualized within the right atrium. B) Clot being removed with distal portion remaining within the PFO. C) Clot in its entirety after removal. 